\title{
Impact of stenting on coronary angioplasty procedures
}

\author{
H S Lee, C Densem, R D Levy, D H Bennett, S G Ray, N H Brooks
}

\begin{abstract}
Objective-To compare patient selection and outcome of coronary angioplasty procedures before and after the widespread availability and use of stents.

Subjects and methods-Group 1 consisted of 252 consecutive patients and group 2 comprised 389 patients who underwent angioplasty between April 1993 and March 1994, and April 1995 and March 1996, respectively, in a tertiary cardiothoracic centre. Clinical variables were collected before the procedures. Endpoints included in-hospital death, the need for repeat coronary angiography, repeat angioplasty, and coronary artery bypass surgery. Lesions were classified under American Heart Association/American College of Cardiology criteria in 100 randomly selected patients from each group.
\end{abstract}

Results-311 and 482 angioplasty procedures were performed in patients from groups 1 and 2, respectively. One or more stents were deployed in nine $(4 \%)$ and 179 $(46 \%, p<0.01)$ patients, respectively. The success rate was higher in group 2 than in group 1 patients $(483 / 523(92 \%) v 274 / 372$ $(88 \%)$, respectively, $\mathrm{p}<0.05)$. There were significantly more single vessel angioplasty procedures $(198 / 252(79 \%) v 272 / 389$ $(70 \%), p<0.05)$, type A lesions (30/116 $(26 \%) v 19 / 130(15 \%), \mathrm{p}<0.05)$, patients with stable angina $(220 / 252(87 \%) v 311 / 389$ $(80 \%), p<0.05)$, and fewer acute myocardial infarction patients $(1 / 252(0 \%) v$ $12 / 389(3 \%), p<0.05)$ treated in group 1 than in group 2, respectively. Similar numbers of angioplasty were performed in the left anterior descending, left circumflex, and right coronary arteries. There were no significant differences in the in-hospital mortality or the need for repeat coronary angiography, angioplasty, or bypass surgery at 24 hours or six months after the initial procedure.

Conclusion-Patients undergoing angio-

Department of

Cardiology,

Wythenshawe Hospital,

Southmoor Road,

Wythenshawe M23 9LT,

Manchester, UK

H S Lee

C Densem

R D Levy

D H Bennett

S G Ray

N H Brooks

Correspondence to:

Dr Lee.

Accepted for publication 26 November 1997 pression that stenting has made a valuable impact on the practice of angioplasty. (Heart 1998;80:505-508)

Keywords: coronary angioplasty; stents; revascularisation; ischaemic heart disease; interventional cardiology
The deployment of stents as part of the percutaneous transluminal coronary angioplasty (PTCA) procedure was first reported in $1987 .{ }^{1}$ Initially, stents were used primarily for the management of coronary dissections caused by the balloon (or other device), thereby reducing the need for emergency coronary artery bypass grafting (CABG). However, randomised trials have shown that elective stenting can reduce the rate of restenosis ${ }^{2-4}$ and the need for reintervention on the target lesion. ${ }^{2}$ Since then the use of coronary stents has increased exponentially, ${ }^{5}$ and in our hospital stents are currently implanted in over $60 \%$ of procedures.

The randomised trials were carried out in highly selected patients with relatively discreet lesions and the results cannot necessarily be extrapolated to predict the effect of the availability of stents on overall clinical practice. In view of the high cost of these devices and the potential for complications to result from their deployment, we undertook a study in which we compared patient selection and outcome during a year before the widespread adoption of stents and during the first year in which all operators in our centre were experienced in their use.

\section{Methods}

\section{STUDY POPULATION}

Consecutive patients who underwent PTCA in two, 12 months periods, before and after the introduction and widespread use of stents in our centre, were studied. Group 1 consisted of 252 consecutive patients who underwent angioplasty between April 1993 and March 1994, and group 2 comprised 389 patients who had their PTCA carried out between April 1995 and March 1996.

One hundred patients were randomly selected from each group for more detailed study. Their coronary angiograms were reviewed and

Table 1 Patients'characteristics

\begin{tabular}{lccl}
\hline & $\begin{array}{l}\text { Group } 1 \\
(n=100)\end{array}$ & $\begin{array}{l}\text { Group } 2 \\
(n=100)\end{array}$ & $p$ \\
\hline Diabetes mellitus & 9 & 5 & NS \\
Current smoker & 7 & 7 & NS \\
Ever smoked & 73 & 77 & NS \\
Renal failure & 1 & 1 & NS \\
Hypertension & 27 & 35 & NS \\
Hypercholesterolaemia & 69 & 64 & NS \\
\hline
\end{tabular}

Table 2 Indications for PTCA

\begin{tabular}{llll}
\hline Indications & $\begin{array}{l}\text { Group 1 } \\
(n=252)\end{array}$ & $\begin{array}{l}\text { Group 2 } \\
(n=389)\end{array}$ & $p$ \\
\hline Stable angina & $220(87 \%)$ & $311(80 \%)$ & $<0.05$ \\
Unstable angina & $31(12 \%)$ & $66(17 \%)$ & NS \\
Acute MI & $1(0 \%)$ & $12(3 \%)$ & $<0.05$ \\
\hline
\end{tabular}


Table 3 Coronary artery characteristics

\begin{tabular}{|c|c|c|c|}
\hline & $\begin{array}{l}\text { Group } 1 \\
(n=252)\end{array}$ & $\begin{array}{l}\text { Group } 2 \\
(n=389)\end{array}$ & $p$ \\
\hline \multicolumn{4}{|l|}{ Number of vessels PTCA } \\
\hline 1 & $198(79 \%)$ & $273(70 \%)$ & $<0.05$ \\
\hline 2 & $48(19 \%)$ & $98(25 \%)$ & NS \\
\hline 3 & $6(2 \%)$ & $18(5 \%)$ & NS \\
\hline \multicolumn{4}{|l|}{ Vessels involved } \\
\hline LM & $0(0 \%)$ & $6(2 \%)$ & NS \\
\hline LAD & $126(50 \%)$ & $205(53 \%)$ & NS \\
\hline RCA & $71(28 \%)$ & $130(33 \%)$ & NS \\
\hline $\mathrm{LCx}$ & $55(22 \%)$ & $64(16 \%)$ & NS \\
\hline Grafts & $8(3 \%)$ & $5(1 \%)$ & NS \\
\hline \multicolumn{4}{|c|}{$\begin{array}{l}\mathrm{LM} \text {, left main; } \mathrm{LAD} \text {, left anterior descending artery; RCA, right } \\
\text { coronary artery; LCx, left circumflex artery. }\end{array}$} \\
\hline \multicolumn{4}{|l|}{ Table 4 Lesion type } \\
\hline & Group 1 & Group 2 & $p$ \\
\hline \multirow{2}{*}{$\begin{array}{l}\text { Number of patients } \\
\text { Number of lesions dilated }\end{array}$} & 100 & 100 & \\
\hline & 116 & 130 & \\
\hline \multirow[t]{3}{*}{ Lesion type $\quad$ A } & $30(26 \%)$ & $19(15 \%)$ & $<0.05$ \\
\hline & $57(49 \%)$ & $78(60 \%)$ & NS \\
\hline & $29(25 \%)$ & $33(25 \%)$ & NS \\
\hline
\end{tabular}

lesions were classified according to American Heart Association/American College of Cardiology classification. ${ }^{6}$

\section{ANGIOPLASTY PROCEDURE}

Coronary angioplasty was performed using standard techniques. All patients were treated with aspirin and intravenous heparin was administered at the start of the procedure. Warfarin was used for patients who were stented until September 1995 when ticlopidine was introduced. Coronary stents in use during the study period were the Palmaz-Schatz (Johnson \& Johnson Interventional system, Miami, Florida, USA), Micro (Advanced Vascular Engineering, Santa Rosa, California, USA) and Wiktor (Medtronic Inc, Kerrade, the Netherlands.)

CLINICAL VARIABLES AND OUTCOME MEASURED Clinical variables, including age, sex, a history of diabetes mellitus, hypertension, hypercholesterolaemia (total cholesterol more than

Table 5 Repeat angiography, revascularisation, and in-hospital mortality

\begin{tabular}{llll}
\hline & Group 1 $(n=252)$ & Group 2 $(n=389)$ & $p$ \\
\hline 24 hours & $6(2 \%)$ & $6(2 \%)$ & NS \\
ReAng & $5(2 \%)$ & $14(4 \%)$ & NS \\
PTCA & $6(2 \%)$ & $9(2 \%)$ & NS \\
CABG & & & \\
6 months & $42(17 \%)$ & $60(15 \%)$ & NS \\
ReAng & $49(19 \%)$ & $70(18 \%)$ & NS \\
RePTCA & $17(7 \%)$ & $21(7 \%)$ & NS \\
CABG & $61(24 \%)$ & $86(22 \%)$ & NS \\
CABG or PTCA & $93(37 \%)$ & $137(35 \%)$ & NS \\
CABG, PTCA or ReAng & $4(2 \%)$ & $8(2 \%)$ & NS \\
In-hospital mortality & &
\end{tabular}

24 hours and 6 months, repeat procedures within 24 hours and six months.

Table 6 Events rate within group 2 patients

\begin{tabular}{lllll}
\hline & & Stented & Not stented & $p$ \\
\hline Number of patients & 179 & 209 & \\
$>1$ stent deployed & & 30 & - & \\
24 hours & ReAng & $6(3 \%)$ & $0(0 \%)$ & $<0.05$ \\
& PTCA & $3(2 \%)$ & $10(5 \%)$ & NS \\
6 months & CABG & $4(2 \%)$ & $5(2 \%)$ & NS \\
& ReAng & $36(20 \%)$ & $24(11 \%)$ & $<0.05$ \\
& RePTCA & $21(12 \%)$ & $48(23 \%)$ & $<0.01$ \\
& CABG & $7(4 \%)$ & $14(7 \%)$ & NS \\
\hline
\end{tabular}

24 hours and 6 months, repeat procedures within 24 hours and six months.
$5.2 \mathrm{mmol} / \mathrm{l}$ ), smoking, and renal failure were collected before the procedures. Details of the procedure and of subsequent PTCA and CABG, and any subsequent angiography, were also obtained. Clinical end points were the need for repeat coronary angiography, rePTCA, CABG, and in-hospital mortality. Patients with recurrent symptoms who proceeded directly to repeat PTCA were not recorded as having repeat angiography.

STATISTICAL ANALYSIS

The $\chi^{2}$ test with Yate's correction was used to assess the significance of difference between the two group of patients.

\section{Results}

PATIENTS

During the first and second periods of the study, 311 and 482 PTCA procedures were performed in 252 and 389 patients, respectively. One or more stents were deployed in nine (4\%) group 1 patients and 179 (46\%) group 2 patients $(\mathrm{p}<0.01)$. Their mean $(\mathrm{SD})$ age was $57(9)$ and 58 (9) years with $193(77 \%)$ and $299(77 \%)$ male patients in the respective groups. The characteristics of the 100 patients whose angiograms were reviewed are summarised in table 1 .

INDICATIONS AND SUCCESS RATE

Significantly more PTCAs were performed for stable angina in group 1 patients and more were performed for acute myocardial infarction in group 2 patients (table 2). The success rate of $92 \%(483 / 523)$ for group 2 was significantly higher than for group 1 patients $(88 \%$, $274 / 372)(p<0.05)$.

VESSELS NUMBER AND TYPE

There were significantly more single vessel PTCAs performed in patients in group $1 \mathrm{com}-$ pared to group 2 (table 3). Similar numbers of PTCAs was performed in the left anterior descending, left circumflex, and right coronary arteries. No angioplasty was performed in the left main stem artery in patients in group 1, but six had PTCA to that vessel in group 2. There were significantly more type A lesions dilated in group 1 patients than in group 2 patients (table 4).

REPEAT CORONARY ANGIOGRAPHY, REVASCULARISATION, AND IN-HOSPITAL MORTALITY

There were no significant differences in the in-hospital mortality or the rate of repeat coronary angiography, re-PTCA or CABG at 24 hours or at six months after the initial procedure (table 5).

OUTCOME OF PATIENTS RECEIVING STENTS

In group 2, the 179 patients who received one or more stents had a significantly lower re-PTCA rate at six months than those without stents $(21(12 \%) v 48(23 \%), \mathrm{p}<0.01)$. The CABG rates were similar between the patients (table 6). 


\section{Discussion}

The use of coronary stents has increased rapidly since the results of randomised trials suggested that elective stenting improves outcome in and after PTCA procedures. ${ }^{2-4}$ The BENESTENT (Belgian Netherlands stent) study group ${ }^{2}$ randomised 520 patients with stable angina and single coronary artery stenosis to either Palmaz-Schatz stent implantation or standard balloon angioplasty. Compared to the stent group, there were significantly more patients in the angioplasty group who reached a primary endpoint of either death, cerebrovascular accident, myocardial infarction, the need for CABG, or a further PTCA at the previously dilated site. The difference in clinical events were largely caused by a reduced need for a second PTCA in the stent group. The STRESS (stent restenosis study) investigators similarly randomised 410 patients to elective PalmazSchatz stent or balloon angioplasty. ${ }^{3}$ The result showed a higher success rate in the stent group in association with a larger immediate gain in the minimal luminal diameter, but by six months, the residual gain was only $0.18 \mathrm{~mm}$ $(\mathrm{p}<0.01)$. There was a non-significant reduction of clinical end points and the need for further revascularisation of the initial target lesion in the stented patients.

Stenting increases the cost of coronary angioplasty by as much as $50-100 \% \cdot^{7-11}$ In the STRESS trial, the average cost of procedures with stents was US $\$ 1200$ more than for balloon angioplasty. Correspondingly, the in-hospital costs were US $\$ 2200$ more per patient. ${ }^{7}$ Restenosis with coronary stents seems to be caused primarily by neointimal hyperplasia ${ }^{12}$ and can be troublesome to manage. In addition there is a risk of subacute stent occlusion, which may complicate procedures. For these reasons, stents are still primarily deployed when PTCA results are suboptimal or as a bailout device in coronary artery dissection or acute closure. ${ }^{13}{ }^{14}$ It is important to ascertain what impact this therapeutic approach, rather than elective stenting of all suitable lesions, has on coronary angioplasty procedures.

A study by Altmann et al compared the angioplasty complications after introduction of coronary stents. ${ }^{14}$ Despite a very low stent rate of only $4 \%$, they concluded that the major complication rate was reduced by more than $50 \%$ in the stenting era. In our study, coronary stents were deployed in a much larger number of patients, $46 \%$ in group $2 v 4 \%$ in group 1 , and we had anticipated that our study would show a reduction in both early complications and in the need for late reintervention. Our surprise in finding a comparable frequency of such complications led to the more detailed analysis of risk factors in the two cohorts.

Patients undergoing angioplasty in our centre since the introduction of stents had features associated with an increased risk of early complications and late recurrence compared with those treated before stents became widely available. Multivessel PTCA was performed significantly more frequently in group $2(30 \%)$ than in group 1 patients $(21 \%)$. There were six left main stem PTCA procedures in group 2 while none was attempted in group 1 patients. More complex angioplasty was attempted in the stenting era with fewer type A and more type B lesions being revascularised. Primary angioplasty for acute myocardial infarction was performed more commonly in the group 2 . The complication rates for conventional PTCA is higher in patients with unstable angina than in those in more stable condition. ${ }^{15} \mathrm{~A}$ study by Marzocchi et al suggests that stenting reduces these complication rates with results comparable to PTCA performed for stable angina. ${ }^{15}$ In our study, there were significantly more patients with stable angina in group 1 than in group 2. Despite these adverse features the rate of periprocedural complications, the need for early and late reinvestigation, and the subsequent requirement for reinvestigation were similar in the two groups. Moreover, the primary success rate was higher in the stent era. These observations support the widely held clinical impression that the introduction of stents has widened the indications for PTCA, and provide some justification for the increased cost associated with their use.

The rate of revascularisation was lower in the group 2 patients who received a stent than in the patients without a stent. Thus, patients who were unsuitable for or did not receive a stent had a high revascularisation rate of $30 \%$ at six months. This observation might be explained in part by the smaller diameter of many vessels considered unsuitable for stenting and is not, in itself, evidence of clinical benefit from the technique.

\section{Conclusions}

The introduction of stents in coronary angioplasty procedures was associated with increasing treatment of higher risk patients. Despite this, the initial success rate was higher, and the in-hospital mortality and the need for repeat revascularisation did not increase in the stenting era.

1 Sigwart U, Puel J, Mirkovith V, et al. Intravascular stents to prevent occlusion and restenosis after transluminal angioplasty. N Engl F Med 1987;316:701-6.

2 Serruys PW, Jaegere P, Kiemeneij F, et al. A comparison of balloon-expandable-stent with balloon angioplasty in patients with coronary artery disease. $N$ Engl f Med 1994; 331:489-95.

3 Fischman DL, Leon MB, Baim DS, et al. A randomised comparison of coronary-stent placement and balloon angioplasty in the treatment of coronary artery disease. $N \mathrm{Engl} F$ Med 1994;331:496-501.

4 Versaci F, Gaspardone A, Tomai F, et al. A comparison of coronary artery stenting with angioplasty for isolated stenosis of the proximal left anterior descending coronary artery. N Engl f Med 1997;336:817-22.

5 Rodriguez A, Ambrose JA. Do we require a cure for 'stentRodriguez A, Ambrose JA. Do we require
mania'. F Am Coll Cardiol 1996;28:827-9.

6 Ryan TJ, Faxon DP, Gunnar RM, et al. Guidelines for percutaneous transluminal coronary angioplasty: a report of the American College of Cardiology/American Heart Association task force on assessment of diagnostic and therapeutic cardiovascular procedures (subcommittee on percutaneous transluminal angioplasty). $7 \mathrm{Am}$ Coll Cardiol 1988;12:529-45

7 Cohen DJ, Krumholz HM, Sukin CA, et al. In-hospital and one year economic outcomes after coronary stenting or balloon angioplasty. Circulation 1995;92:2480-7.

8 Dick PC, Popma JJ, Muller DW, et al. In-hospital cost associated with new percutaneous coronary devices. Am $\mathcal{F}$ Cardiol 1991;68:879-85.

9 Topol EJ. Caveats about elective coronary stenting. $N$ Engl $\mathcal{F}$ Med 1994;331:539-41.

10 Lazzam C, Lazzam LM, Mclaughlin PR, et al. Implications of higher initial in-hospital costs on restenosis rates with newer devices [abstract]. Circulation 1992;86(suppl I):I-44. 
11 Weintraub WS, Waksman R, Bernard J, et al. The influence of new devices on the costs of interventional procedures [abstract]. Circulation 1994:90(suppl I) $:$ I-4 .

12 Dangas G, Fuster V. Management of restenosis after coronary intervention. Am Heart f 1996;132:428-36.

13 Eeckhout E, Goy JJ, Vogt P, et al. Complications and followup after intracoronary stenting: critical analysis of a 6-year single-centre experience. Am Heart f 1994;127:262-72.
14 Altmann DB, Racz M, Battleman DS, et al. Reduction in angioplasty complications after the introduction of coronary stents: results from a consecutive series of 2242 patients. Am Heart f 1996;132:503-7.

15 Marzocchi A, Piovaccari G, Marrozzini C, et al. Results of coronary stenting for unstable versus stable angina pectoris. Am f Cardiol 1997;79:1314-18.

\section{Dual atrial pathology as an incidental finding on thoracic computed tomography and echocardiography}

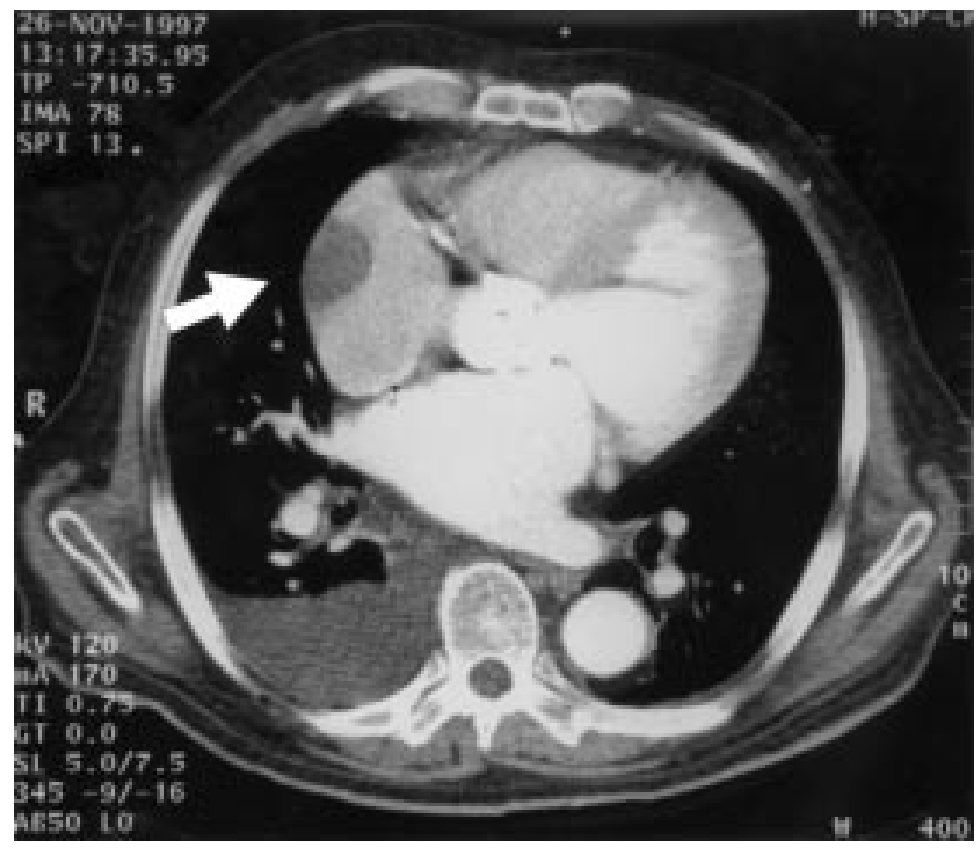

An 81 year old man with known severe aortic stenosis and atrial fibrillation, in the presence of very poor ventricular function, was admitted to hospital complaining of severe chest pain. The pain was sharp, associated with nausea, and radiated to his back. Computed tomography (CT) of his thorax excluded thoracic aortic dissection but did show a right atrial mass and possible left atrial thrombus. Transoesophageal echocardiography showed a right atrial venous cast and a left atrial thrombus. A venous cast represents thrombus that has formed in a deep vein assuming its shape. The hollow cast has become dislodged from the deep vein and become trapped within the right atrium-presumably becoming enmeshed within vestigial inferior vena cava valve structures or the Chiari network. While both pathologies are seen in echocardiographic practice it is unusual for them to occur together in an anticoagulated patient.
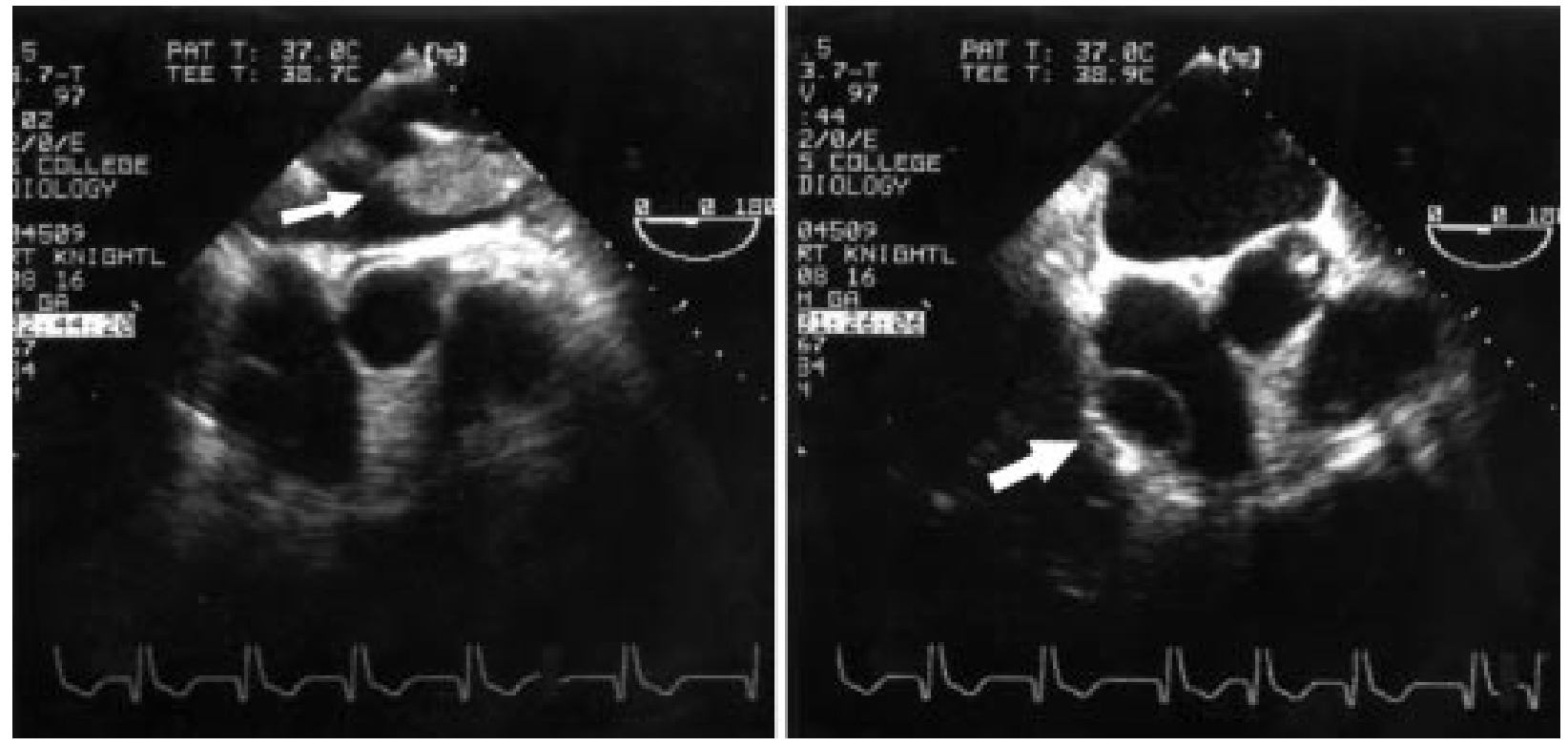

J M COTTON A BROWN M J MONAGHAN 